\title{
Utility of Anti-DSF70 Antibodies to Predict Connective Tissue Disease in Patients Originally Presenting with Idiopathic Interstitial Pneumonia
}

\author{
Yan Lyu ${ }^{a, b}$ Eda Boerner ${ }^{a}$ Dirk Theegartenc ${ }^{c}$ Josune Guzman ${ }^{d}$ \\ Michael Kreuter ${ }^{\mathrm{e}} \quad$ Ulrich Costabel ${ }^{\mathrm{a}} \quad$ Francesco Bonella $^{\mathrm{a}}$ \\ ${ }^{a}$ Center for Interstitial and Rare Lung Diseases, Department of Pneumology, Ruhrlandklinik University Hospital, \\ University of Duisburg-Essen, Essen, Germany; ${ }^{\mathrm{b}}$ Tangshan Center for Disease Control and Prevention, Tangshan, PR \\ China; ' Institute of Pathology, University Hospital Essen, University of Duisburg-Essen, Essen, Germany; ${ }^{\mathrm{d}}$ General

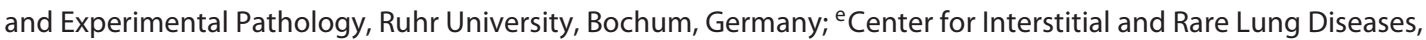 \\ Department of Pneumology, Thoraxklinik, University of Heidelberg, and German Center for Lung Research (DZL), \\ Heidelberg, Germany
}

\section{Keywords}

Antibodies · Autoimmune diseases · Interstitial lung

disease $\cdot$ Connective tissue disease

\begin{abstract}
Background: Anti-DFS70 antibodies, corresponding to the dense fine speckled antinuclear antibody (ANA) pattern in HEp-2 substrates, have been observed in chronic inflammatory conditions, cancer and in healthy individuals but in only a small percentage of patients with connective tissue diseases (CTD). Objectives: The study was aimed to investigate the possible role of Anti-DFS70 antibodies to distinguish CTD associated interstitial lung disease (CTD-ILD) from idiopathic interstitial pneumonia (IIP) and to explore potential correlations between anti-DFS70 antibodies and clinical parameters. Methods: Serum samples were collected from 49 healthy controls (HC), 35 scleroderma-ILD (SSc-ILD) patients as negative controls for anti-DFS70 antibody, and 260 patients with the initial diagnosis IIP including 100 nonspecific interstitial pneumonia (NSIP) and 160 idiopathic pulmonary fibrosis (IPF) patients. ANA pattern was identified by indirect
\end{abstract}

(C) 2019 S. Karger AG, Basel

E-Mail karger@karger.com www.karger.com/res immunofluorescence on HEp-2 cells and anti-DFS70 antibodies were measured in serum by ELISA. Results: Serum anti-DFS70 antibodies were less frequently seen in ILD and SSc-ILD patients compared to HCs. Thirty-seven patients (34 initial idiopathic NSIP and 3 initial IPF patients) developed CTD during 24 months of follow-up, most of them combined with ANA positivity and anti-DFS70 antibody negativity. Anti-DFS70 antibody positivity was not significantly different between CTD-ILD and idiopathic ILD. Conclusions: The frequency of serum anti-DFS70 antibody is markedly decreased in patients with ILDs. Anti-DFS70 antibodies may be useful to predict CTD development in ILD patients.

(c) 2019 S. Karger AG, Basel

\section{Introduction}

Connective tissue diseases (CTDs) are characterized by autoimmune phenomena and immune-mediated organ dysfunction [1]. The lung is a vulnerable target of autoimmune mediated injury in patients with CTD because of its abundant vasculature and large content of 
connective tissue. Interstitial lung disease (ILD) is a common pulmonary involvement, which has been shown to occur in all kinds of CTDs, especially in patients with systemic sclerosis (scleroderma [SSc]) [2, $3]$.

When ILDs occur in association with CTDs, they may present before, during or after the full manifestation of a given CTD [4]. If presenting before, ILDs may be the only manifestation and precede the extrapulmonary CTD manifestation by several months, sometimes by more than 5 years $[5,6]$. Since the radiological and histological characteristics of CTD-ILDs are similar to their idiopathic counterparts $[7,8]$, autoimmune screening is recommended in all patients with suspected idiopathic interstitial pneumonia (IIP). The serologic evaluation should include the measurement of rheumatoid factor, anti-cyclic citrullinated peptide, and antinuclear antibody (ANA) screening [9].

ANAs are not specific for CTDs, since approximately $20 \%$ of apparently healthy individuals have a positive ANA test [10]. The limited specificity has been one of the most important drawbacks of the HEp-2 indirect immunofluorescence (IIF) assay as an ANA screening test for CTD [11]. The main target of the positive ANA pattern seen in healthy individuals is the dense fine speckled 70 antibody (anti-DFS70 antibody) [10, 11]. Anti-DFS70 antibodies are predominantly IgG and recognize a protein that can be visualized by IIF microscopy as dense fine speckles in the nucleoplasm of cells in interphase, typically excluding the nucleolus, with increased staining intensity of condensed mitotic chromosomes [12]. They have been reported in patients with a variety of chronic inflammatory conditions, in cancer patients, and also in apparently healthy individuals $[10,13,14]$. In contrast, the prevalence of anti-DFS70 antibodies in CTD patients is rather low $[15,16]$.

Dellavance et al. [17] evaluated over 13,000 ANA positive samples of a general clinical laboratory by IIF and immunoblot and found that anti-DFS70 autoantibodies were seen in $37 \%$ of samples and more commonly associated with non autoimmune conditions than with systemic autoimmune diseases. Interestingly, in regard to the long-term outcome, after an average follow-up of 4 years, none of the healthy individuals with isolated anti-DFS70 antibody reactivity later developed systemic autoimmune diseases [11].

The aim of the current study was to investigate the frequency of serum anti-DFS70 antibodies and a possible correlation with ANA status in patients with idiopathic pulmonary fibrosis (IPF) and idiopathic non- specific interstitial pneumonia (NSIP). Additionally, we investigated the potential role of anti-DFS70 antibody to distinguish between CTD-ILD and IIP and to predict CTD development in patients diagnosed initially as IIP.

\section{Methods}

\section{Disposition of the Patients}

We retrospectively studied 260 ILD patients initially diagnosed as IPF $(n=160)$ or idiopathic NSIP $(n=100)$ seen in our institution between April 2007 and August 2013.

Two groups of controls were included: the healthy control (HC) group composed of 49 blood donors and 35 SSc-ILD patients who served as negative controls as having ANA positivity with specific subtypes other than anti-DFS70 [18].

The patients with IPF and NSIP were diagnosed based on clinical, radiographic, and histopathologic findings according to the ATS/ERS criteria of 2011 and 2013 respectively [9, 19]. The SSc patients were diagnosed based on the 2013 classification criteria [20]. Out of 260 patients, 64 (24.6\%) ILD patients had histological confirmation, 37 with IPF and 27 with NSIP.

During follow-up of the IPF and NSIP patients, the diagnosis of CTD was made by rheumatologists according to current criteria for the respective disease [20-23]. All patients had a follow-up time of at least 2 years after blood sampling.

\section{ANA and Anti-DFS70 Antibody Laboratory Assays}

Serum samples were obtained at time of first evaluation and were stored at $-80^{\circ} \mathrm{C}$ until analysis. $\mathrm{LDH}$ was routinely measured in the serological laboratory of our institution.

The ANA-IIF assay was performed on HEp-2 cells (Euroimmun AG, BIOCHIPS TITERPLANE ${ }^{\circledR}$-Technique, EUROPLUS ${ }^{\circledR}$, ANA-Global Test, FA1510-2010-1, Lübeck, Germany). ANA were considered positive with a titer above 1:80.

The concentration of serum anti-DFS70 antibody at baseline was measured using a commercially available ELISA kit (Medical and Biological Laboratories Co., Ltd., Fujioka City, Japan). The ELISA was performed according to the manufacturer's instructions (https://www.mblintl.com/assets/7808_DFS70_200902_4final. pdf). The cut-off for positivity was set at $400 \mathrm{U} / \mathrm{ml}$ in this study, calculated as twice the standard deviation above the average of the negative control group (35 SSc-ILD patients).

\section{Pulmonary Function Tests and Blood Gas Analysis}

Measurements were performed at the time of the serum sample collection. Pulmonary function tests included forced vital capacity (FVC), forced expiratory volume in one second $\left(\mathrm{FEV}_{1}\right)$, total lung capacity (TLC), and diffusing capacity of the lung for carbon monoxide (DLCo). Values were expressed as percentages of predicted normal values. Blood gas analysis included partial pressure of oxygen in arterial blood $\left(\mathrm{PaO}_{2}\right)$, arterial carbon dioxide tension $\left(\mathrm{PaCO}_{2}\right)$, arterial oxygen saturation $\left(\mathrm{SaO}_{2}\right)$, and alveolar-arterial oxygen gradient $\left(\mathrm{AaDO}_{2}\right)$.

\section{Statistics}

Parametric data were presented as mean \pm SEM. Student's t test was used to compare continuous variables between 2 groups; chi-
Lyu/Boerner/Theegarten/Guzman/ Kreuter/Costabel/Bonella 
Table 1. Demographics and patients' characteristics of the studied groups

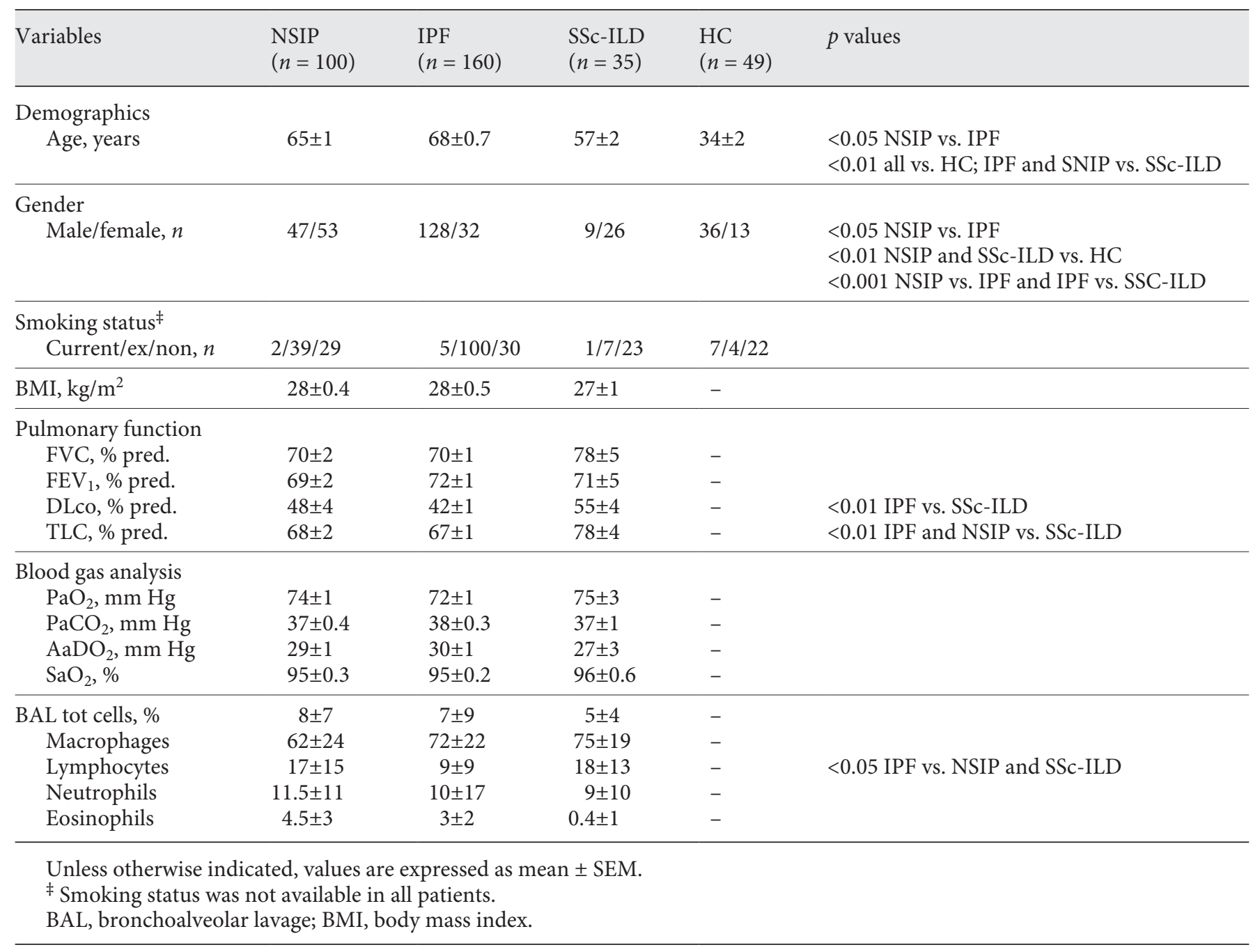

square test was done for categorical variables. One-way ANOVA and least significant difference or Dunnett's post hoc tests were performed for multiple comparisons. A logistic regression was performed to assess whether ANA+/antiDSF70- was independently associated with the development of CTD by using backward conditional method regression with Hosmer-Lemeshow goodness of fit test. $p$ values lower than 0.05 were considered statistically significant. SPSS 17.0 (SPSS Inc., Chicago, IL, USA) was used for statistical analysis.

\section{Results}

\section{Characteristics of Studied Subjects}

The demographic, functional, and laboratory characteristics of the studied subjects are shown in Table 1. Comorbidities in the studied ILD subjects are shown in the online supplemental Table 1 (for all online suppl. material, see www.karger.com/doi/10.1159/000496483). During 24 months of follow-up, 37 of 260 ILD patients (14\%) developed CTD ( 3 initial IPF and 34 initial idiopathic NSIP patients). Of these 37 patients, 22 developed rheumatoid arthritis (RA), 7 SSc, 4 antisynthetase syndrome, 2 Sjögren's syndrome, 1 mixed CTD, 1 undifferentiated CTD. All the 3 CTD-UIP patients developed RA.

Acute exacerbation occurred in 47 patients, 34 with IPF and 13 with NSIP.

\section{ANA and Anti-DFS70 Antibody at Baseline}

ANA was positive in $47 \%$ of NSIP patients compared to $32 \%$ of IPF patients $(p<0.05)$. In both the NSIP and the IPF patients, ANA positivity was significantly lower 
Table 2. Prevalence of ANA and anti-DFS70 antibody in studied groups

\begin{tabular}{|c|c|c|c|}
\hline Diagnosis & $\begin{array}{l}\text { ANA (+), } \\
n(\%)\end{array}$ & $\begin{array}{l}\text { Anti-DFS70 (+), } \\
n(\%)\end{array}$ & $p$ value (between disease groups) \\
\hline \multicolumn{4}{|l|}{ ILD } \\
\hline \multicolumn{4}{|l|}{ Initial classification } \\
\hline $\operatorname{NSIP}(n=100)$ & $47(47)$ & $12(12)$ & $<0.05$ NSIP vs. all groups \\
\hline $\operatorname{IPF}(n=160)$ & $51(32)$ & $31(19)$ & $<0.001 \mathrm{IPF}$ vs. HC and SSc-ILD \\
\hline \multicolumn{4}{|c|}{ Reclassification after 24 months } \\
\hline $\operatorname{IIP}(n=223)$ & $73(33)$ & $37(17)$ & $\begin{array}{l}<0.001 \text { IIP vs. CTD-ILD, } \\
\text { SSc-ILD and HC (ANA) } \\
<0.01 \text { vs. HC (DFS-70) }\end{array}$ \\
\hline CTD-ILD $(n=37)$ & $25(68)$ & $6(16)$ & $<0.05$ vs. HC \\
\hline SSc-ILD $(n=35$ & $29(83)$ & $2(6)$ & $<0.01$ vs. $\mathrm{HC}$ \\
\hline $\mathrm{HC}(n=49)$ & $0(0)$ & $17(35)$ & \\
\hline
\end{tabular}

than in the SSc-ILD patients ( $p<0.001$; Table 2$)$. No effect of gender, age, and smoking status on ANA positivity was observed (data not shown).

Anti-DFS70 antibodies were positive in $12 \%$ of NSIP patients and $19 \%$ of IPF patients $(p>0.05)$. Anti-DFS70 antibody positivity was significantly lower in both the NSIP and IPF groups than in HC ( $p<0.05$, respectively), and tended to be higher than in SSc-ILD $(p>0.05$, respectively; Table 2). In the total individuals of ILD patients, the prevalence of anti-DFS70 antibodies was not different between men and women ( $17 \mathrm{vs.} 15 \%, p>0.05)$ and appeared to be stable across 3 age groups ( $17 \%$ in $\leq 60$ years, $16 \%$ in $61-70$ years, and $17 \%$ in more than 70 years, $p>0.05$ ).

\section{ANA and Anti-DFS70 Antibody Positivity According to Development of CTD}

After a follow-up time of 24 months, of the 260 patients initially diagnosed as idiopathic ILD, 223 remained as IIP, and 37 developed CTD (Table 2). The prevalence of ANA positivity in the final IIP group was significantly lower than in the final CTD-ILD group (33 vs. $68 \% p<0.05$; Table 2). Within the NSIP group, ANA were positive in $35 \%$ iNSIP patients, which was a significantly lower percentage than that in CTD-NSIP (71\%) and SSc-ILD ( $83 \%)$ patients ( $p<0.001$, respectively). The ANA positive percentage in IPF-UIP $(32 \%)$ was also significantly lower than that in SSc-ILD $(p<0.001)$, but similar to CTD-UIP (33\%, $p>0.05$; Fig. 1$)$. Although the difference between CTD-UIP and SSc-ILD was significant, when considering the small number of CTD-UIP $(n=3)$, the result is questionable.

The prevalence of anti-DFS70 antibody positivity in the IIP group (17\%) was significantly lower than in HCs

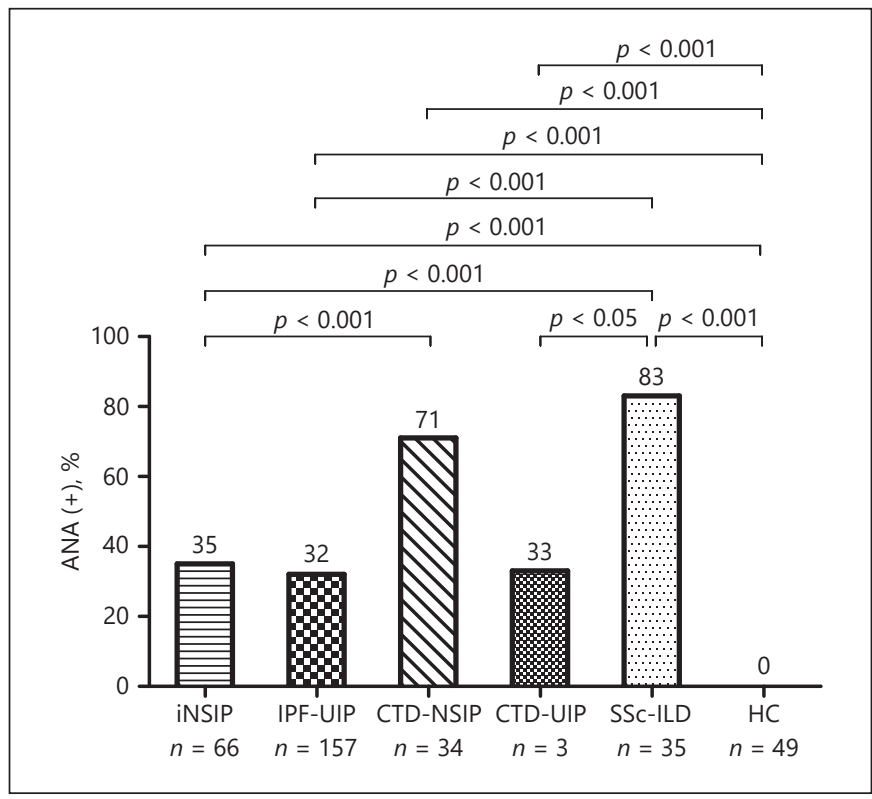

Fig. 1. Prevalence of ANA positivity according to CTD development. Data expressed as percentage.

(35\%, $p<0.05)$ but not significantly different from CTD-ILD (16\%, $p>0.05$; Table 2). Anti-DFS70 antibodies were positive in $11 \%$ iNSIP patients, significantly less than in HC $(p<0.05)$ but not significantly different from CTD-NSIP (15\%) and SSc-ILD (6\%), $p>$ 0.05 respectively. The anti-DFS70 antibody positive percentage of IPF-UIP (19\%) was also significantly lower than $\mathrm{HC}(p<0.05)$ and similar to CTD-UIP $(33 \%, p>0.05)$ but higher than that in SSc-ILD ( $p=$ 0.06; Fig. 2).
Lyu/Boerner/Theegarten/Guzman/ Kreuter/Costabel/Bonella 


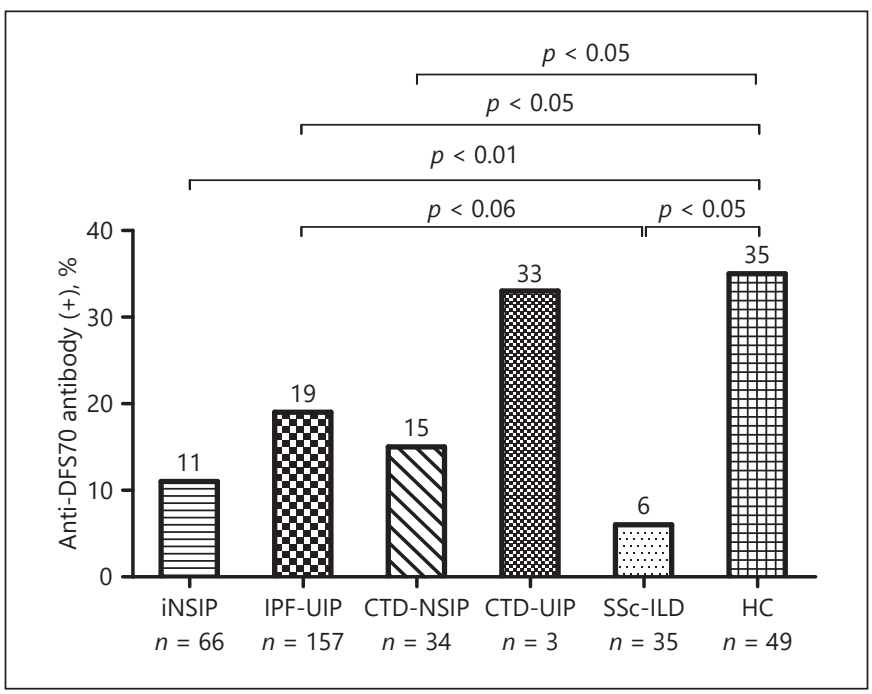

Fig. 2. Prevalence of anti-DFS70 antibody positivity according to CTD development. Data expressed as percentage.

\section{Relationship between ANA and Anti-DFS70 Antibodies}

Among the ANA positive ILD patients, $20 \%$ were antiDFS70 antibody positive. This was not significantly different from the ANA negative individuals who were positive in $14 \%$.

At baseline, among the ANA positive ILD patients, the prevalence of anti-DFS70 antibody positivity in IPF $(25 \%)$ was significantly higher than that in SSc-ILD $(3 \%, p<$ $0.05)$, and was also higher, but not significantly, than in NSIP (15\%, $p>0.05)$. Among the ANA negative subjects, $\mathrm{HC}$ had the highest percentage of anti-DFS70 antibody positivity (35\%), significantly higher than NSIP or IPF (15 and $17 \%, p<0.05$ respectively; Fig. 3 ).

After follow-up, among the ANA positive subjects, the prevalence of anti-DFS70 antibody positivity in IIP (22\%) tended to be higher than in CTD-ILD (16\%, $p$ > $0.05)$. Among the ANA negative subjects, the prevalence of anti-DFS70 antibody positivity was similar in IIP and in CTD-ILD ( $14 \%$ and $17 \%, p>0.05$ respectively; Fig. 3).

\section{Frequency of CTD Development According to ANA and Anti-DFS70 Antibody Status}

Among the 260 ILD patients, 98 (38\%) were ANA positive at baseline. The frequency of CTD development was significantly higher in those ILD patients who were ANA positive $(25 / 98,26 \%)$ than ANA negative $(12 / 162,7 \%)$, $p<0.001$. The ANA titres were not different between the IIP patients who developed CTD and those who did not.
Among the IIP patients, 129 out of 223 (58\%) were ANA (-)/DFS70 (-). This was a significantly higher percentage than that in CTD-ILD patients $(10 / 37,27 \%), p<$ 0.001 . Conversely, 21 of 37 CTD-ILD patients $(57 \%)$ were ANA (+)/DFS70 (-), a significantly higher proportion than that in IIP patients (57/223, 26\%), $p<0.001$ (Table 3).

A logistic regression was performed to assess whether ANA+/antiDSF70 - status was independently associated with the development of CTD-ILD (online suppl. Table 2). We included age, gender, smoking status, HRCT pattern and BAL lymphocytes as covariates, since patients who developed CTD in follow-up had significantly higher BAL lymphocytes at baseline than those who did not ( $21 \pm 5$ vs. $12 \pm 9 \%, p=0.003$ ).

ANA+/antiDSF70 - status and NSIP HRCT pattern were both significantly associated with CTD development (online suppl. Table 1). According to this model based on ANA+/antiDSF70 - status and NSIP HRCT pattern, $89.4 \%$ of patients who developed CTD over time could be correctly classified.

\section{Correlations between Anti-DFS70 Antibody Status and Clinical/Laboratory Parameters}

In NSIP patients, there were no differences in clinical characteristics between the NSIP groups according to anti-DFS70 antibody status except for a significantly lower arterial $\mathrm{PaCO}_{2}$ in anti-DFS70 (+) patients than in anti-DFS70 (-) patients $(35 \pm 0.8$ vs. $38 \pm 0.4 \mathrm{~mm} \mathrm{Hg}$, $p<0.05)$.

In IPF patients, serum LDH was significantly lower in anti-DFS70 antibody $(+)$ than in anti-DFS70 antibody $(-)$ patients ( $252 \pm 10$ vs. $286 \pm 6, p<0.05$; online suppl. Table $3)$. In regard to pulmonary function parameters, DLco (\%pred.) was significantly higher in anti-DFS70 antibody $(+)$ than that in anti-DFS70 antibody (-) IPF patients ( $48 \pm 3$ vs. $41 \pm 1, p<0.05$ ), and the $\mathrm{AaDO}_{2}$ was significantly lower in anti-DFS70 antibody $(+)$ than that in antiDFS70 antibody (-) IPF patients ( $26 \pm 2$ vs. $31 \pm 1, p<$ 0.05 ; online suppl. Table 3 ).

We did not observe any association between DFS-70 antibodies and BAL differential cell count. In particular, DSF-70 negative IPF patients had the same BAL lymphocytes as DSF-70 positive patents (10.5 \pm 9 vs. $9.5 \pm 9 \%$ respectively, $p=0.66$; online suppl. Table 3 ). Similarly, whole blood cellular subpopulations did not vary according to anti-DFS70 antibody status (data not shown). Finally, we did not observe any association between DFS-70 status and comorbidities (online suppl. Table 1) or with acute exacerbation of ILD $(p=0.093)$. 


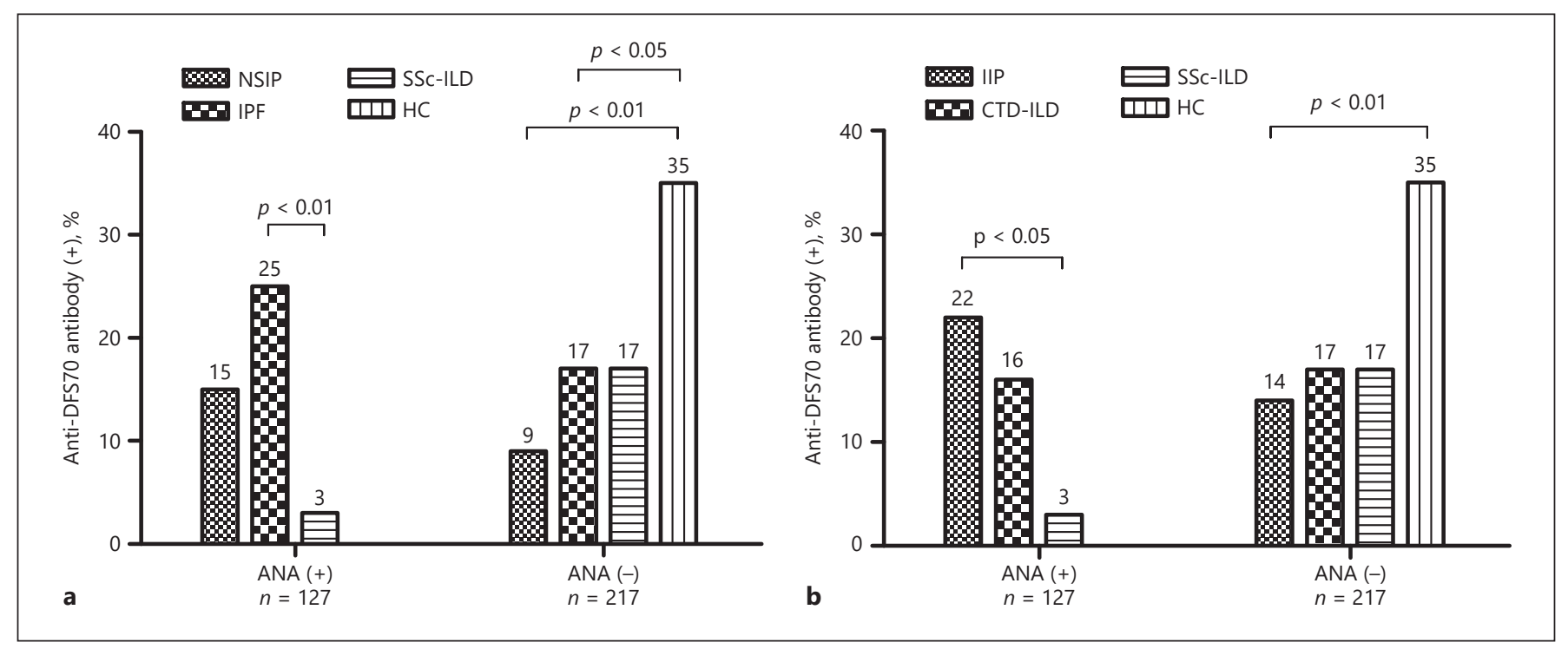

Fig. 3. Frequency of anti-DFS70 antibody positivity according to ANA status at baseline (a) and at end of followup (b). Data expressed as percentage (\%).

\section{Discussion}

In the current study, we found that serum anti-DFS70 antibodies are less prevalent in ILD patients than in HCs. During follow-up, ANA positive ILD patients with negative anti-DFS70 antibody developed CTD more frequently than those who were anti-DFS70 positive. In IPF, the patients with anti-DFS70 antibody positivity seemed to have less impaired pulmonary function. To the best of our knowledge, this is the first study that investigated the role of anti-DFS70 antibodies in ILD patients.

In the 1960s, Turner-Warwick was one of the first to describe that ANA are positive in nearly $50 \%$ of ILD patients [24]. In our study, positive ANAs were observed in $47 \%$ of NSIP and $32 \%$ of IPF patients. The observed frequency is consistent with the existing literature [25]. In our CTD-ILD patients, ANA positivity was seen in $68 \%$ which is relatively low for a CTD cohort. This may be due to the composition of our CTD-ILD population, with $59 \%$ being RA patients. RA is in general not an ANA-associated disease, since ANA positivity has been reported in only up to $30 \%$ of patients with RA [26]. Despite the fact that the prevalence of ANAs has been reported to be higher in healthy women than that in healthy men [27, 28 ] and higher in elderly than in younger healthy individuals $[29,30]$, in the ILD subjects of our study we did not observe these associations.

Anti-DFS70 antibodies have been investigated in only a few lung disorders. In a cohort of atopic dermatitis pa-
Table 3. Association of ANA and anti-DFS70 antibody status with the development of CTD, assessed 24 months after initial evaluation

\begin{tabular}{llll}
\hline & $\begin{array}{l}\text { IIP } \\
(n=223), n(\%)\end{array}$ & $\begin{array}{l}\text { CTD-ILD } \\
(n=37), n(\%)\end{array}$ & $\begin{array}{l}p \\
\text { value* }\end{array}$ \\
\hline ANA (+)/DFS70 (+) & $16(7)$ & $4(11)$ & \\
ANA (+)/DFS70 (-) & $57(26)$ & $21(57)^{*}$ & $<0.001$ \\
ANA (-)/DFS70 (+) & $21(9)$ & $2(5)$ & $<0.001$ \\
ANA (-)/DFS70 (-) & $129(58)$ & $10(27)^{*}$ & \\
\hline$*$ Calculated by using chi-square test. & \\
\hline
\end{tabular}

tients, $16 \%$ of the patients with asthma were DFS70 positive compared with $30 \%$ of those with atopic dermatitis only and $0 \%$ of healthy subjects [31]. Yamada et al. [38] found that in patients with panuveitis, including sarcoidosis patients, anti-DFS70 positivity was seen in $67 \%$ of patients versus $22 \%$ of HCs.

In some studies, anti-DFS70 antibodies were more prevalent or had higher titers in females than in males [10, 31]. Our study, in agreement with others, did not find such gender difference [32]. Variations in cohort collection and disease composition may explain the discrepancy. An age dependency was shown in a study of 918 healthy individuals, where more than $90 \%$ of the DFS positive subjects were younger than 50 years [11]. How-
Lyu/Boerner/Theegarten/Guzman/ Kreuter/Costabel/Bonella 
ever, this was not confirmed in another study [32]. Also in our study, the status of anti-DFS70 antibodies showed no correlation with age.

The prevalence of anti-DFS70 antibodies has been reported to vary, but consistent findings are that they are present in healthy ANA positive individuals even when ANA reach moderate or high titers, and that they are rarely found in patients with CTD $[17,33,34]$. Fitch-Rogalsky et al. [35] investigated 643 patients with a positive ANA and found that $15 \%$ were anti-DFS70 antibody positive and $91 \%$ of these did not have an autoimmune disease. In a study of routine ANA screening DFS and traditional fine speckled patterns were the major ANA-IIF patterns, and $61 \%$ of DFS positivity was seen in non autoimmune conditions [17]. Our study confirms this for patients with ILDs. Among the ANA positive ILD patients, anti-DFS70 antibody positivity was seen in $22 \%$ of IIP patients, compared to $16 \%$ of the patients who developed CTD. This suggests that anti-DFS70 antibody positivity decreases the likelihood of a CTD-ILD. The regression analysis confirmed the association between the presence of ANA positivity and DFS70 negativity together with an NSIP pattern at baseline and the development of CTD during follow up. These variables combined were able to identify $85.8 \%$ of patients who developed CTD. Whether this approach can be routinely used to identify patients at risk for CTD development among those with ILD needs further validation.

To avoid the low specificity of ANA-IIF test as screening test for systemic autoimmune rheumatic disease, subsequent immunoassays for specified antibodies are usually done, but there is no consistency in the recommendations for the use of autoantibodies and diagnostic algorithms in different serological laboratories [36]. It has been recommended to include Ro/SSA, La/SSB, Jo-1, Scl70, Th/To, RNA-Polymerase III, Sm, dsDNA (SLE) and CCP in the serological examination of ILD patients [37]. Since by now more than 150 different autoantibodies have been discovered, in consideration of feasibility and economic costs, it is impossible to include all CTD associated ANAs into ANA screening ELISA tests. Therefore, it would be useful to have a biomarker, which would exclude CTD in patients with ILD and positive ANA serology but without symptoms or signs of CTD. Such a biomarker could result in considerable cost-savings by adding accuracy to the ANA screening test. As such, Anti-DFS70 antibody is one of the best candidates, since it seems to be helpful in discriminating between subjects with and those without autoimmune disease among ANA positive patients.

Anti-DFS70 Antibodies in ILD
The clinical and biological significance of anti-DFS70 autoantibody is still puzzling. The higher prevalence of anti-DFS70 antibodies in healthy subjects than in autoimmune diseases supports the hypothesis that these autoantibodies can serve as protective or natural autoantibodies [33]. On the other hand, since the antigen could possibly trigger the elicitation and accumulation of autoantibodies, the presence of anti-DFS70 antibodies in apparently healthy individuals may be indicative of an undetected chronic inflammatory response. In the current study, we found that in IPF patients, the anti-DFS70 antibody negative patients showed higher levels of LDH. A strong trend, though statistically not significant due to the small number of patients with anti-DFS70 antibody positivity, was also seen in NSIP patients. LDH is a nonspecific marker of tissue injury widely used to monitor the course of acute lung injury, indicating that a higher degree of tissue injury is possibly associated with a reduction of anti-DFS70 antibodies. Whether anti-DFS70 antibody has a pathogenic role or is merely a bystander in the pathogenesis of ILDs is unclear at present.

Our study has several limitations. First, we did not include healthy subjects with ANA positivity as controls; therefore, we cannot draw any conclusion on the presence of DFS-70 antibodies in healthy individuals. Our controls were blood donors therefore been screened for autoimmune diseases. Second, the exact ANA-IIF pattern as well as ANA subtypes was not available in all individuals, so that it is not possible to investigate further correlations with DFS-70 antibodies in CTD-ILD patients. Second, the number of CTD-UIP patients was very small $(n=3)$ because few IPF patients developed CTD. Third, measurement of DFS70 levels in BALF/tissue was not performed and should be done in further studies. Comparing lung tissue expression of DFS70 versus circulating levels of anti-DFS70 antibodies would be important to explore the potential function of this antigen-antibody system in the pathogenesis of ILDs. Finally, we did not perform a longitudinal analysis to correlate DFS-70 status and lung function tests over time or ILD outcome; this should be considered in future studies.

In conclusion, the prevalence of anti-DFS70 antibody was highest in healthy subjects and decreased in patients with ILDs and SSc-ILD. Most of the ILD patients who developed CTD during follow-up were shown to be characterized by ANA positivity combined with anti-DFS70 antibody negativity in the presence of an NSIP pattern on HRCT. The potential use of this antibody in the clinical routine to reclassify patients with initially diagnosed idiopathic ILD needs to be further investigated. 


\section{Acknowledgement}

None.

\section{Statement of Ethics}

Written informed consent was obtained from the ILD patients and controls. The study was approved by the local IRB (RLK 23.06.2015)

\section{Financial Disclosure and Conflicts of Interest}

The authors declare that they have no potential conflicts of interest to disclose.

\section{Funding Sources}

This study was funded by Arbeitsgemeinschaft zur Förderung der Pneumologie an der Ruhrlandklinik (AFPR) and by Lungenfibrose e.V, Germany.

\section{Authors' Contributions}

Y.L. and F.B. contributed to the conception and design of the study, analysis and interpretation of the data, and drafting and finalization of the manuscript. E.B. contributed to the collection of samples. D.T. and J.G contributed to interpretation of the data and drafting of the manuscript. M.K. contributed to the conception and design of the study and interpretation of the data. U.C. contributed to the conception of the study, interpretation of the data, statistical results, drafting and finalizing manuscript. All authors have read and approved of the final manuscript.

\section{References}

1 Olson AL, Brown KK, Fischer A. Connective tissue disease-associated lung disease. Immunol Allergy Clin North Am. 2012 Nov;32(4): 513-36.

2 de Lauretis A, Veeraraghavan S, Renzoni E. Review series: Aspects of interstitial lung disease: connective tissue disease-associated interstitial lung disease: how does it differ from IPF? How should the clinical approach differ? Chron Respir Dis. 2011;8(1):53-82.

3 Fischer A, du Bois R. Interstitial lung disease in connective tissue disorders. Lancet. 2012 Aug;380(9842):689-98.

4 Tzelepis GE, Toya SP, Moutsopoulos HM. Occult connective tissue diseases mimicking idiopathic interstitial pneumonias. Eur Respir J. 2008 Jan;31(1):11-20.

5 Homma Y, Ohtsuka Y, Tanimura K, Kusaka H, Munakata M, Kawakami Y, et al. Can interstitial pneumonia as the sole presentation of collagen vascular diseases be differentiated from idiopathic interstitial pneumonia? Respiration. 1995;62(5):248-51.

6 Lynch DA. Lung disease related to collagen vascular disease. J Thorac Imaging. 2009 Nov; 24(4):299-309.

7 Buzan MT, Pop CM. State of the art in the diagnosis and management of interstitial lung disease. Clujul Med. 2015;88(2):116-23.

8 Hwang JH, Misumi S, Sahin H, Brown KK, Newell JD, Lynch DA. Computed tomographic features of idiopathic fibrosing interstitial pneumonia: comparison with pulmonary fibrosis related to collagen vascular disease. J Comput Assist Tomogr. 2009 May-Jun 33(3):410-5.

9 Raghu G, Collard HR, Egan JJ, Martinez FJ, Behr J, Brown KK, et al.; ATS/ERS/JRS/ALAT Committee on Idiopathic Pulmonary Fibrosis. An official ATS/ERS/JRS/ALAT state- ment: idiopathic pulmonary fibrosis: evidence-based guidelines for diagnosis and management. Am J Respir Crit Care Med. 2011 Mar; 183(6):788-824.

10 Watanabe A, Kodera M, Sugiura K, Usuda T, Tan EM, Takasaki Y, et al. Anti-DFS70 antibodies in 597 healthy hospital workers. Arthritis Rheum. 2004 Mar;50(3):892-900.

11 Mariz HA, Sato EI, Barbosa SH, Rodrigues SH, Dellavance A, Andrade LE. Pattern on the antinuclear antibody-HEp-2 test is a critical parameter for discriminating antinuclear antibody-positive healthy individuals and patients with autoimmune rheumatic diseases. Arthritis Rheum. 2011 Jan;63(1):191200.

12 Ochs RL, Mahler M, Basu A, Rios-Colon L, Sanchez TW, Andrade LE, et al. The significance of autoantibodies to DFS70/LEDGFp75 in health and disease: integrating basic science with clinical understanding. Clin Exp Med. 2016 Aug;16(3):273-93.

13 Meroni PL, Schur PH. ANA screening: an old test with new recommendations. Ann Rheum Dis. 2010 Aug;69(8):1420-2.

14 Daniels T, Zhang J, Gutierrez I, Elliot ML, Yamada B, Heeb MJ, et al. Antinuclear autoantibodies in prostate cancer: immunity to LEDGF/p75, a survival protein highly expressed in prostate tumors and cleaved during apoptosis. Prostate. 2005 Jan;62(1):1426.

15 Ganapathy V, Casiano CA. Autoimmunity to the nuclear autoantigen DFS70 (LEDGF): what exactly are the autoantibodies trying to tell us? Arthritis Rheum. 2004 Mar;50(3): 684-8.

16 Mahler M, Hanly JG, Fritzler MJ. Importance of the dense fine speckled pattern on HEp-2 cells and anti-DFS70 antibodies for the diag- nosis of systemic autoimmune diseases. Autoimmun Rev. 2012 Jul;11(9):642-5.

17 Dellavance A, Viana VS, Leon EP, Bonfa ES, Andrade LE, Leser PG. The clinical spectrum of antinuclear antibodies associated with the nuclear dense fine speckled immunofluorescence pattern. J Rheumatol. 2005 Nov;32(11): 2144-9.

18 Karsten C, Nadja R, Sebastian R, Michael M. DFS70 antibodies-biomarkers for the exclusion of ANA-associated autoimmune rheumatic diseases. J Lab Med. 2015;38:299-308.

19 Travis WD, Costabel U, Hansell DM, King TE Jr, Lynch DA, Nicholson AG, et al.; ATS/ERS Committee on Idiopathic Interstitial Pneumonias. An official American Thoracic Society/European Respiratory Society statement: update of the international multidisciplinary classification of the idiopathic interstitial pneumonias. Am J Respir Crit Care Med. 2013 Sep;188(6):733-48.

20 van den Hoogen F, Khanna D, Fransen J, Johnson SR, Baron M, Tyndall A, et al. 2013 classification criteria for systemic sclerosis: an American college of rheumatology/European league against rheumatism collaborative initiative. Ann Rheum Dis. 2013 Nov;72(11): 1747-55.

21 Tan EM, Cohen AS, Fries JF, Masi AT, McShane DJ, Rothfield NF, et al. The 1982 revised criteria for the classification of systemic lupus erythematosus. Arthritis Rheum. 1982 Nov;25(11):1271-7.

22 Aletaha D, Neogi T, Silman AJ, Funovits J, Felson DT, Bingham CO 3rd, et al. 2010 Rheumatoid arthritis classification criteria: an American College of Rheumatology/European League Against Rheumatism collaborative initiative. Arthritis Rheum. 2010 Sep; 62(9):2569-81. 
23 Shiboski SC, Shiboski CH, Criswell L, Baer A, Challacombe S, Lanfranchi H, et al.; Sjögren's International Collaborative Clinical Alliance (SICCA) Research Groups. American College of Rheumatology classification criteria for Sjögren's syndrome: a data-driven, expert consensus approach in the Sjögren's International Collaborative Clinical Alliance cohort. Arthritis Care Res (Hoboken). 2012 Apr; 64(4):475-87.

24 Turner-Warwick M, Doniach D. Auto-antibody studies in interstitial pulmonary fibrosis. BMJ. 1965 Apr;1(5439):886-91.

25 Kang BH, Park JK, Roh JH, Song JW, Lee CK, Kim M, et al. Clinical significance of serum autoantibodies in idiopathic interstitial pneumonia. J Korean Med Sci. 2013 May;28(5): $731-7$.

26 Aitcheson CT, Peebles C, Joslin F, Tan EM. Characteristics of antinuclear antibodies in rheumatoid arthritis. Reactivity of rheumatoid factor with a histone-dependent nuclear antigen. Arthritis Rheum. 1980 May;23(5): 528-38.

27 Fernandez SA, Lobo AZ, Oliveira ZN, Fukumori LM, P rigo AM, Rivitti EA. Prevalence of antinuclear autoantibodies in the serum of normal blood dornors. Rev Hosp Clin Fac Med Sao Paulo. 2003 Nov-Dec;58(6):315-9.

28 Hayashi N, Koshiba M, Nishimura K, Sugiyama D, Nakamura T, Morinobu S, et al.
Prevalence of disease-specific antinuclear antibodies in general population: estimates from annual physical examinations of residents of a small town over a 5 -year period. Mod Rheumatol. 2008;18(2):153-60.

29 Candore G, Di Lorenzo G, Mansueto P, Melluso $M$, Fradà $G$, Li Vecchi $M$, et al. Prevalence of organ-specific and non organ-specific autoantibodies in healthy centenarians. Mech Ageing Dev. 1997 Mar;94(1-3):18390.

30 Hurme M, Korkki S, Lehtimäki T, Karhunen PJ, Jylhä M, Hervonen A, et al. Autoimmunity and longevity: presence of antinuclear antibodies is not associated with the rate of inflammation or mortality in nonagenarians. Mech Ageing Dev. 2007 May-Jun;128(5-6): 407-8.

31 Ochs RL, Muro Y, Si Y, Ge H, Chan EK, Tan EM. Autoantibodies to DFS $70 \mathrm{kd} /$ transcription coactivator p75 in atopic dermatitis and other conditions. J Allergy Clin Immunol. 2000 Jun;105(6 Pt 1):1211-20.

32 Mahler M, Parker T, Peebles CL, Andrade LE, Swart A, Carbone Y, et al. Anti-DFS70/ LEDGF antibodies are more prevalent in healthy individuals compared to patients with systemic autoimmune rheumatic diseases. J Rheumatol. 2012 Nov;39(11):2104-10.

33 Miyara M, Albesa R, Charuel JL, El Amri M, Fritzler MJ, Ghillani-Dalbin P, et al. Clinical phenotypes of patients with anti-DFS70/ LEDGF antibodies in a routine ANA referral cohort. Clin Dev Immunol. 2013;2013: 703759.

34 Pazini AM, Fleck J, dos Santos RS, Beck ST. Clinical relevance and frequency of cytoplasmic and nuclear dense fine speckled patterns observed in ANA-HEp-2. Rev Bras Reumatol. 2010 Nov-Dec;50(6):655-60.

35 Fitch-Rogalsky C, Steber W, Mahler M, Lupton T, Martin L, Barr SG, et al. Clinical and serological features of patients referred through a rheumatology triage system because of positive antinuclear antibodies. PLoS One. 2014 Apr;9(4):e93812.

36 Mahler M, Fritzler MJ. The clinical significance of the dense fine speckled immunofluorescence pattern on HEp-2 cells for the diagnosis of systemic autoimmune diseases. Clin Dev Immunol. 2012;2012:494356.

37 Bahmer T, Romagnoli M, Girelli F, Claussen M, Rabe KF. The use of auto-antibody testing in the evaluation of interstitial lung disease (ILD) - A practical approach for the pulmonologist. Respir Med. 2016 Apr;113: 80-92.

38 Yamada K, Senju S, Shinohara T, Nakatsura T, Murata Y, Ishihara M, et al. Humoral immune response directed against LEDGF in patients with VKH. Immunol Lett. 2001 Oct; 78(3):161-8. 
DuEPublico

Duisburg-Essen Publications online

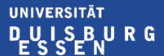

offen im Denken

0 | $\begin{aligned} & \text { universitäts } \\ & \text { bibliothek }\end{aligned}$

This text is made available via DuEPublico, the institutional repository of the University of Duisburg-Essen. This version may eventually differ from another version distributed by a commercial publisher.

DOI: $\quad 10.1159 / 000496483$

URN: urn:nbn:de:hbz:465-20220225-095658-0

This publication is with permission of the rights owner freely accessible due to an Alliance licence and a national licence (funded by the DFG, German Research Foundation) respectively.

(c) 2019 S. Karger AG, Basel. All rights reserved. 